\title{
Economic Growth Efficiency and Productivity Constrained by Government Debts
}

\author{
Jianxin Wu, Jingjing Qian \\ School of Economic, Jinan University, Guangzhou, China \\ Email: 13229483158@163.com
}

How to cite this paper: $\mathrm{Wu}, \mathrm{J} . \mathrm{X}$. and Qian, J.J. (2018) Economic Growth Efficiency and Productivity Constrained by Government Debts. Modern Economy, 9, 1338-1359. https://doi.org/10.4236/me.2018.97086

Received: July 2, 2018

Accepted: July 28, 2018

Published: July 31, 2018

Copyright (c) 2018 by authors and Scientific Research Publishing Inc. This work is licensed under the Creative Commons Attribution International License (CC BY 4.0).

http://creativecommons.org/licenses/by/4.0/

\begin{abstract}
This paper analyzes the panel data of 60 countries during the period 1990-2014. It employs non-radial and non-angled slack-based measure (SBM) method to count the economic growth efficiency and inefficiency sources under government debt constraints. The results show that traditional efficiency is usually higher than economic growth efficiency, and the latter can better reflect real economic situation. In addition, debt inefficiency is the main cause of declining economic growth efficiency in all countries, and it has the greatest impact on developing countries. Meanwhile, this paper also adopts the global reference Global-Malmquist-Luenberger (GML) index to measure total factor productivity (TFP) and further decomposes it into technological changes and efficiency changes. It is found that technological progress and efficiency improvement are the main driving forces for enhancing total factor productivity.
\end{abstract}

\section{Keywords}

Economic Growth Efficiency, Economic Total Factor Productivity, SBM Method, GML Index

\section{Introduction}

In order to cope with the Great Depression caused by the Second World War, governments of all countries have adopted expansionary fiscal policies to get rid of the long-term depressed economic environment. During this period, the ideas advocated by Keynesianism dominated the economic theory and proposed to expand the fiscal deficit and the size of government debt. These measures will cause a multiplier effect, pull the total economic demand and stimulate the rapid development of the economy. After the outbreak of the financial crisis in 2008, 
the Keynesian thoughts have more and more important impact on governments and the scale of fiscal deficits has rapidly expanded. However, the expansion of government debt has not permanently brought about sustained economic growth. The financial crisis resulted in the bankruptcy of the three largest banks in Iceland in the same year and the total debt amount was 9 times GDP. Then it refused to repay the debts at the expense of national credit and became the first country to collapse due to debt after the financial crisis. In 2009, three major rating agencies downgraded Greece's credit rating which accelerated the process of the Greek debt crisis. This incident became the trigger for the sovereign debt crisis in the euro zone countries and the leading euro country's giant, Germany, was suffered a heavy setback. With the continuous spread of the government debt crisis, the United States, as the only super economy in the world, also contained great credit risks. The unremitting outbreak of debt crisis had aroused strong doubts about the view that government debt promotes sustainable economic development.

The lessons of history and the results of a large number of academic studies tell us that the expansion of government debt can, to a certain extent, facilitate the rapid development of economy, while the continuous accumulation of government debt will crowd out private investment. What's more, the debt crisis will lead to economic and social unrest and the country will enter a stage of poor development with low growth and low productivity. Therefore, whether it is possible to continuously raise the scale of government debt without considering government debt constraints in order to seek economic development in the process of production, and the heterogeneity of economic growth will be after taking account into government debt constraints. These issues have been discussed by scholars and will be researched across the board in the paper.

At present, most scholars tend to take energy and resources as constraints in the production process and seldom take into account the constraints of government debt. However, governments in various countries will invest a part of government debt into productive activities, which indicates that government debt is productive in the production process. This article selects the economic growth efficiency and TFP under the government debt restriction as the research object and then analyzes the economic performance under the government debt constraint more comprehensively via dividing the economic performance into two aspects. The paper adopts SBM model and GML index as research methods based on previous literature, and includes government debt into the production function from the national level. To be further, government debts are used as the undesired outputs in the production process to study the economic growth efficiency and productivity under the constraints of government debt and compare them with the traditional economic growth efficiency and productivity, providing a new perspective for future economic performance research. Secondly, all countries are divided into three major regional countries-developed countries, transition countries (referring to the transition from planned economy to mar- 
ket economy) and developing countries (excluding transition countries, the same below) and conduct thorough analysis to discuss the otherness between efficiency and productivity among different regions. Furthermore, the author emphasizes the importance of technological progress and efficiency improvement in promoting productivity by decomposing TFP into technological changes and efficiency changes. Thirdly, this paper incorporates financial development factor into the influences of economic growth efficiency and productivity, highlighting the significance of financial development.

The other chapters of the paper are organized as follows. The next part of this article describes the literature review about the relationship between government debt and economic growth because the current literatures have few studies on the economic growth efficiency and productivity under government debt constraints. The third part introduces research method, employing SBM method and GML index to measure economic growth efficiency and productivity respectively. The fourth part presents the data sources of this paper and the selection of related indicators. The fifth part analyzes comparatively the calculation results of economic growth efficiency and productivity about 60 countries and three major regional countries. The sixth part, through the tobit model and the fixed effect model for regression analysis, studies the influence factors of economic growth efficiency and productivity under the government debt constraints. The last part is the conclusion and policy significance.

\section{The Literature Review}

There are many domestic and foreign literatures on the study of government debt and economic growth. Especially, the relevant literatures published in 2010 and 2011 by Reinhart and Rogoff [1] [2] have attracted much attention. They discussed the link between debt, economic growth, and inflation by analyzing data from 44 countries and found that there is a threshold effect between government debt and economic growth. When the proportion of government debt to GDP is less than $90 \%$, the impact of government debt on economic growth is weak. While the ratio exceeds $90 \%$, government debt will have a significant negative effect on economic growth. The situation of government debt in developed and emerging economies is similar, and there is no significant relationship between high debt levels and inflation. As the level of debt rises to a certain extent, the risk premium begins to increase rapidly, which will reduce people's confidence in the government and thus decrease investment behavior. It is easy to evolve a financial crisis from a crisis of confidence. Most scholars agree with their view that there is indeed a critical value between them, and the marginal economic growth effect of high debt levels is negative above this threshold [3] [4] [5] [6] [7]. However, they questioned the specific threshold of $90 \%$ in RR. Cecchetti et al. found that the critical value was $85 \%$ with OECD countries as sample points and pointed out that the turning point of corporate debt and household debt scale to economic growth were $90 \%$ and $85 \%$ respectively. Minea 
and Parent discovered that there were two thresholds between government debt and economic growth. When government debt is between $90 \%$ and $150 \%$, the conclusion is consistent with RR. However, economic growth and government debt are positively correlated once the threshold surpasses 115\%. Checherita-westphal and Rother also found an inverted U-shaped relationship between the debt ratio and economic growth rate and the debt turning point is about $90 \%$ to $100 \%$ of GDP. Salotti and Trecroci pointed out that the threshold range between developed economies is between $85 \%$ and $90 \%$. Moreover, Checherita-westphal and Rother, Swamy [8] respectively used instrumental variables and autoregressive methods to verify whether there was a two-way causal relationship between debt size and economic growth. The results show that government debt has a long-term impact on economic growth. On this basis, more and more scholars are interested in the channels of government debt for economic growth and the most representative of literature is Calderón and Fuentes [9]. They analyzed from three major aspects: structural factors, domestic policy environment and foreign policy environment and covered human capital, financial development, trade openness, inflation, financial variables and other variables, which indicated that structural factors can buffer the negative effects of high debt on economic growth. On the other hand, Afonso and Jalles [10] adopted panel data from 155 countries to examine the relationship between government debt and TFP and found that higher debt ratios contributed to the growth of TFP.

The successive outbreak of debt crisis in various countries had also attracted the attention of domestic scholars that have done a lot of research on the relationship between government debt and economic growth. However, domestic literatures mostly focused on studying from the domestic or local debt level and relatively few studies from the national level. Similarly, Chinese scholars found the non-linear relationship between government debt and economic growth by empirical analysis, and there is a distinct threshold effect. Liu Jinlin [11] took the government debt data of OECD countries from 2000 to 2009 as sample points and adopted a dynamic panel regression model with a method of generalized moment estimation. The result indicates that the critical value of government debt scale is $88 \%$. When the government debt rate exceeds $88 \%$, the impact of debt scale on economic growth is negative. Therefore, it's possible to mitigate this negative effect by means of reducing the financial deficit or increasing fiscal revenue. Moreover, it is pointed out that the liquidity liabilities of trade dependence, fixed capital formation rate and financial development level have a significant negative effect on economic growth while the inflation rate is significantly positive. Liu Hongzhong et al. [12] employed the same regression method as Liu Jinlin to conclude that there is an inverted U-shaped relationship between government debt level and economic growth in developed and developing countries, both of which have obvious critical points and the critical points are not identical. That is to say, developed and developing countries have different capabilities for debts and the threshold will change dynamically with changes in 
interest rates, inflation, current accounts and financial development indicators. Cheng Yudan and Gong Liutang [13] [14] made use of the system's GMM dynamic panel and robustness analysis method to study the panel datasets of 113 countries. They discovered that the government debts rate has a significant boost on economic growth when the government debts rate of developed countries is less than $35 \%$. Once it exceeds $35 \%$, there is no significant relationship between the two. However, this effect was opposite in developing countries. In addition, they also found an inverted $U$-shaped relationship between government debt and TFP. When the critical point of government debt-to-GDP ratio is $106.5 \%$, higher debt will significantly reduce TFP.

It can be found by combing the literature that government debts have a threshold effect on economic growth and its influence mechanism is more complicated. So far, no unified conclusion has been obtained. However, government debts of every country will be partly used for productive expenditures, such as infrastructure construction, support for enterprise development and research and development of science and technology, which illustrates government debts are productive. Not only that, this paper also explores the performance of economic performance from two perspectives of economic efficiency and productivity and takes government debts as a non-desirable output in the production process from a new perspective to study the economic growth efficiency and productivity under the constraints of government debts.

\section{Research Methods}

1) Measurement of economic growth efficiency-SBM method

The paper mainly includes the government debt indicator in measuring the economic growth efficiency and productivity and considers the expected output and undesired output simultaneously, which requires a multi-input-multiple output model to measure. Sheppard's distance function (SDF) and directional distance function (DDF) can be applied, but the SDF method requires the expected output to change in proportion to the undesired output. In other words, inputs the undesired output cannot be cut down while increasing the desired output. However, the DDF method can solve this problem. The traditional DEA model is radial, dealing with the problem of excess investment and insufficient output. Since it is not possible to measure the entire slack variable, the result is likely to be biased and the efficiency of each decision making unit (DMU) will be overestimated. Tone [15] first proposed a non-radial and non-angular SBM of directional distance function to measure the amount of excess input and output shortage for DMU, and contained all the slack variables into the objective function to carry on more accurate analysis of efficiency. Referring to previous literature [16] [17] [18], this paper uses a non-radial and non-angular SBM method to measure the economic growth efficiency under government debt constraints and the slack variable of input and output of each country. Furthermore, measuring the levels of efficiency can also identify sources of inefficiency. Assuming 
that each country is considered as a decision unit, there are $I=1,2 \ldots$ I decision units. The vector $x$ represents the input of each decision unit, the $y$ vector represents the desired output in production, and the $b$ vector represents undesired output. Moreover, the paper adopts the assumption of constant returns to scale, and then the production possibility set can be defined as:

$$
P=\{(x, y, b) \mid x \geq X \lambda, y \leq Y \lambda, b \geq B \lambda, \lambda \geq 0\}
$$

The above-mentioned production possibility set $P$ must meet the conditions of closed sets and bounded sets. In addition, input and expected outputs should have strong disposition and undesired outputs have weak disposability and zero binding. Weak disposability refers to the reduction of undesired output in the production process and then the expected output will also decrease proportionally. Zero-binding refers to no undesired output in the production process unless the expected output is zero.

Based on the above-mentioned definitions and assumptions, the non-radial and non-angled economic growth efficiency EE can be calculated by the following formula:

$$
\begin{gathered}
E E=\rho^{*}=\min \frac{1-\frac{1}{N} \sum_{n=1}^{N} \frac{s_{n}^{x}}{x_{n, i}}}{1+\frac{1}{M+K}\left(\sum_{m=1}^{M} \frac{s_{m}^{y}}{y_{m, i}}+\sum_{k=1}^{K} \frac{s_{k}^{b}}{b_{k, i}}\right)} \\
\text { s.t. } x_{n, o}=\sum_{i=1}^{I} x_{n, i} \lambda_{i}+s_{n, i}^{x}, \forall n ; y_{m, o}=\sum_{i=1}^{I} y_{m, i} \lambda_{i}-s_{m, i}^{y}, \forall m ; \\
b_{k, o}=\sum_{i=1}^{I} b_{m, i} \lambda_{i}+s_{k, i}^{b}, \forall k ; \quad s^{x} \geq 0, s^{y} \geq 0, s^{b} \geq 0, \lambda_{i} \geq 0, \forall i
\end{gathered}
$$

There into, $\rho^{*}$ represents the efficiency score of each decision unit and its objective function value is between 0 and 1 , which satisfies $0<\rho^{*} \leq 1 . S_{n}^{x} \in R_{+}^{N}$ and $s_{k}^{b} \in R_{+}^{K}$ represent the redundancy of the input and the undesired output respectively, and $s_{m}^{y} \in R_{+}^{M}$ represents the deficiency of the expected output. $\Lambda_{I}$ is the adjustment matrix, $\sum_{i=1}^{I} x_{n, i} \lambda_{I}$ represents the input at the effective forefront, $\sum_{i=1}^{I} y_{m, i} \lambda_{I}$ and $\sum_{i=1}^{I} b_{m, i} \lambda_{I}$ denote the expected output quantity and the undesired output quantity at the effective forefront respectively. Only if $\rho^{*}=1$, $s^{x^{*}}=0, s^{y^{*}}=0, s^{b^{*}}=0$, the decision unit is most effective with the conditions of existing undesired output at the effective forefront and all the redundancy at this time is 0 . That is, there is no problem about redundant surplus of input and undesired output and insufficient output. This indicates that an invalid decision-making unit can be effective by eliminating redundant input and undesired output and increasing the under-production of the desired output. Using the above plan, the index of economic growth efficiency EE under the condition of government debt can be obtained.

In this model, $\sum_{n=1}^{N} \frac{s_{n}^{x}}{x_{n, o}}$ denotes the proportion of the input redundancy to the actual input, that is, the level of inefficiency of the input. Similarly, 
$\sum_{m=1}^{M} \frac{s_{m}^{y}}{y_{m, o}}$ and $\sum_{n=1}^{N} \frac{s_{n}^{x}}{x_{n, o}}$ represent the level of inefficiencies of expected out put and undesired output separately. The following formulas can be used to calculate the inefficiencies of each factor and further analyze the impact of each input and output factor on the economic growth efficiency.

$$
I E_{o}=I E_{o}^{x}+I E_{o}^{y}+I E_{o}^{b}=\sum_{n=1}^{N} \frac{s_{n}^{x}}{x_{n, o}}+\sum_{m=1}^{M} \frac{s_{m}^{y}}{y_{m, o}}+\sum_{k=1}^{K} \frac{s_{k}^{b}}{b_{k, o}}
$$

The formula indicates that the inefficiency value of decision unit $\mathrm{O}$ is equal to the sum of the inefficiencies of each input and output factor, where $I E_{o}$ is the total inefficiency value of decision unit O. Then $I E_{o}^{x}, I E_{o}^{y}$ and $I E_{o}^{b}$ represent the inefficiency of input, expected output and undesired output of decision-making unit.

2) Measurement of total factor productivity-GML index

Although the economic growth efficiency index EE can determine the efficiency level of each decision unit production, $I E_{o}, I E_{o}^{x}, I E_{o}^{y}$ and $I E_{o}^{b}$ can measure the total, input and output inefficiencies respectively. However, they can only explore the economic growth efficiency statically, and the Malmquist-Luenberger index can measure the dynamic changes of TFP in any two periods. The traditional Malmquist index cannot measure the TFP that contains undesired outputs while the expected output is often accompanied by undesired outputs. In order to achieve calculating TFP with both expected and undesired outputs, Chung et al. [19] proposed the Malmquist-Luenberger index to solve this problem based on the directional distance function. However, the traditional Malmquist-Luenberger index faces the problems of transferability and potential linear programming without solution. In response to this problem, Oh [20] measured the TFP of 26 OECD countries through two methods respectively and discovered the global reference technology can avoid the above problems. Therefore, the paper adopts the global reference Malmquist-Luenberger index based on the non-radial and non-angular SBM method and all the investigation periods are included in the production function to construct the production frontier, then the global production possibility set can be expressed as $P^{G}=P^{1} \cup P^{2} \cup \cdots \cup P^{T}$.

This article defines the SBM directional distance function under government debt constraints as follows:

$$
\begin{gathered}
\vec{D}\left(x_{o}^{t}, y_{o}^{t}, b_{o}^{t} ; \vec{g} \mid C R S\right)=\frac{1}{2} \max \left(\frac{1}{N} \sum_{n=1}^{N} \frac{s_{n}^{x}}{g_{n, i}^{x}}+\frac{1}{M+K}\left(\sum_{m=1}^{M} \frac{s_{m}^{y}}{g_{m, i}^{y}}+\sum_{k=1}^{K} \frac{s_{k}^{b}}{g_{k, i}^{b}}\right)\right)(4) \\
\text { s.t. } x_{n, o}=\sum_{i=1}^{I} x_{n, i} \lambda_{i}+s_{n, i}^{x}, \forall n ; y_{m, o}=\sum_{i=1}^{I} y_{m, i} \lambda_{i}-s_{i}^{y}, \forall m ; \\
b_{k, o}=\sum_{i=1}^{I} b_{m, i} \lambda_{i}+s_{i}^{b}, \forall k ; s_{n}^{x} \geq 0, s_{m}^{y} \geq 0, s_{k}^{b} \geq 0, \lambda_{i} \geq 0, \forall i
\end{gathered}
$$

As described above for the SBM method, $(x, y, b)$ represents input, expected output and undesired output respectively, and $\vec{g}=\left(g^{x}, g^{y}, g^{b}\right)$ is the directional vector of $(x, y, b)$. CRS indicates that scale returns are unchanged. Then 
we can further construct the GML index and the formula is as follows:

$$
\begin{gathered}
G M L_{t}^{t+1}=\frac{1+\overrightarrow{D^{G}}\left(x^{t}, y^{t}, b^{t}\right)}{1+\overrightarrow{D^{G}}\left(x^{t+1}, y^{t+1}, b^{t+1}\right)} \\
G M L_{t}^{t+1}=\frac{1+\overrightarrow{D^{t}}\left(x^{t}, y^{t}, b^{t}\right)}{1+\overrightarrow{D^{t+1}}\left(x^{t+1}, y^{t+1}, b^{t+1}\right)} \\
\times\left[\frac{\left(1+\overrightarrow{D^{G}}\left(x^{t}, y^{t}, b^{t}\right)\right) /\left(1+\overrightarrow{D^{t}}\left(x^{t}, y^{t}, b^{t}\right)\right)}{\left(1+\overrightarrow{D^{G}}\left(x^{t+1}, y^{t+1}, b^{t+1}\right)\right) /\left(1+\overrightarrow{D^{t+1}}\left(x^{t+1}, y^{t+1}, b^{t+1}\right)\right)}\right]
\end{gathered}
$$

$\overrightarrow{D^{G}}(x, y, b)$ and $\overrightarrow{D^{t}}(x, y, b)$ are abbreviations for the global and current directional distance functions respectively, and the global ML index is transitive. When the expected output increases and the undesired output decreases the value of GML will be greater than 1, which means that productivity increases. If the value is equal to 1 , it means that the productivity has not changed. And if it is less than 1, it means that the productivity is decreased. The GML index can be decomposed into the product of the technology change index (TECH) and the efficiency change index (EFCH). These two indices respectively represent the shift effects and catch-up effects of the production frontier, thus further analyzing the main causes of the productivity changes, which can be defined as:

$$
\begin{gathered}
\mathrm{TECH}=\frac{\left(1+\overrightarrow{D^{G}}\left(x^{t}, y^{t}, b^{t}\right)\right) /\left(1+\overrightarrow{D^{t}}\left(x^{t}, y^{t}, b^{t}\right)\right)}{\left(1+\overrightarrow{D^{G}}\left(x^{t+1}, y^{t+1}, b^{t+1}\right)\right) /\left(1+\overrightarrow{D^{t+1}}\left(x^{t+1}, y^{t+1}, b^{t+1}\right)\right)} \\
\mathrm{EFCH}=\frac{1+\overrightarrow{D^{t}}\left(x^{t}, y^{t}, b^{t}\right)}{1+\overrightarrow{D^{t+1}}\left(x^{t+1}, y^{t+1}, b^{t+1}\right)} \\
\mathrm{GML}=\mathrm{TECH} \times \mathrm{EFCH}
\end{gathered}
$$

When TECH and EFCH are greater than 1, they indicate technical progress and efficiency improvement respectively. When it is equal to 1 , it means that there is no change in technology and efficiency. If it is less than 1, it means that the technology is deteriorating and the efficiency is deteriorating.

\section{Data Sources and Indicators Selected}

1) Sources of Data

As national level data is currently only updated to 2014 , the paper selects panel data in 60 countries from 1990 to 2014 to study the economic growth efficiency and productivity. The author originally intended to select the top 100 countries in GDP while considering the lack of data in some countries and the impact of outliers, 60 countries are selected as samples. In order to better illustrate the differences in the economic growth efficiency and productivity of countries in different regions, this paper divides the 60 countries into developed countries, transition countries and developing countries. The data in this article mainly comes from PWT9.0 (Penn World Table version 9.0) database, OECD 
database, WEO database and IMF database.

2) Selection of indicators

The input indicators are capital and labor that the most commonly used and essential two-factor input indicators in the production function, so this article uses these two indicators as inputs. Since every country is lack of data on working hours, the annual number of employees in each country is used as a labor input. Capital and labor data are derived from the PWT 9.0 database.

The expected output is real GDP. There are three ways to calculate GDP: production method, income method and expenditure method. This article utilizes the production method to measure the value created by the country in the new period. Moreover, real GDP that has eliminated the impact of inflation can more effectively reflect the total economic output of a country in a particular period. The real GDP data comes from the PWT9.0 database.

The undesired output is government debt. Although the scale of government debt can be a stimulus to economic growth within a certain range, the continuous accumulation of debt will inhibit economic growth in general. Moreover, government debt is mainly invested in productive activities and is productive. Therefore, this paper regards the scale of government debt as undesired output. The scale of government debt is expressed as the ratio of government debt to GDP. This data can be obtained from the IMF's WEO database and the dataset published by Carmen M. Reinhart.

By dividing these 60 countries into developed countries, transition countries and developing countries, a comprehensive comparative analysis of all relevant indicators for all countries and the three major regions is conducted to study the difference of their economic growth efficiency and TFP. To be further, this paper will study the affecting factors of economic growth efficiency and productivity in order to propose effective policies for policy makers, and then better improve the economic growth efficiency and productivity of various countries.

\section{Analysis of Measurement Results}

Based on the above-mentioned research methods and sample data, we can calculate the economic growth efficiency and productivity of 60 countries under government debt constraint from 1990 to 2014, and compare them with the traditional efficiency and productivity without considering government debt, which demonstrates the importance of considering government debt constraints on economic growth efficiency and productivity.

1) Analysis of Economic Growth Efficiency

Figure 1 depicts the evolutionary trends of the economic growth efficiency and traditional efficiency of all countries and regional countries during the inspection period. With the exception of 2009, the economic growth efficiency and traditional efficiency of all countries and regional countries were slowly growing during the sample period. Both of them suddenly dropped in 2009 and then further increased and one possible reason was that the financial crisis had a 


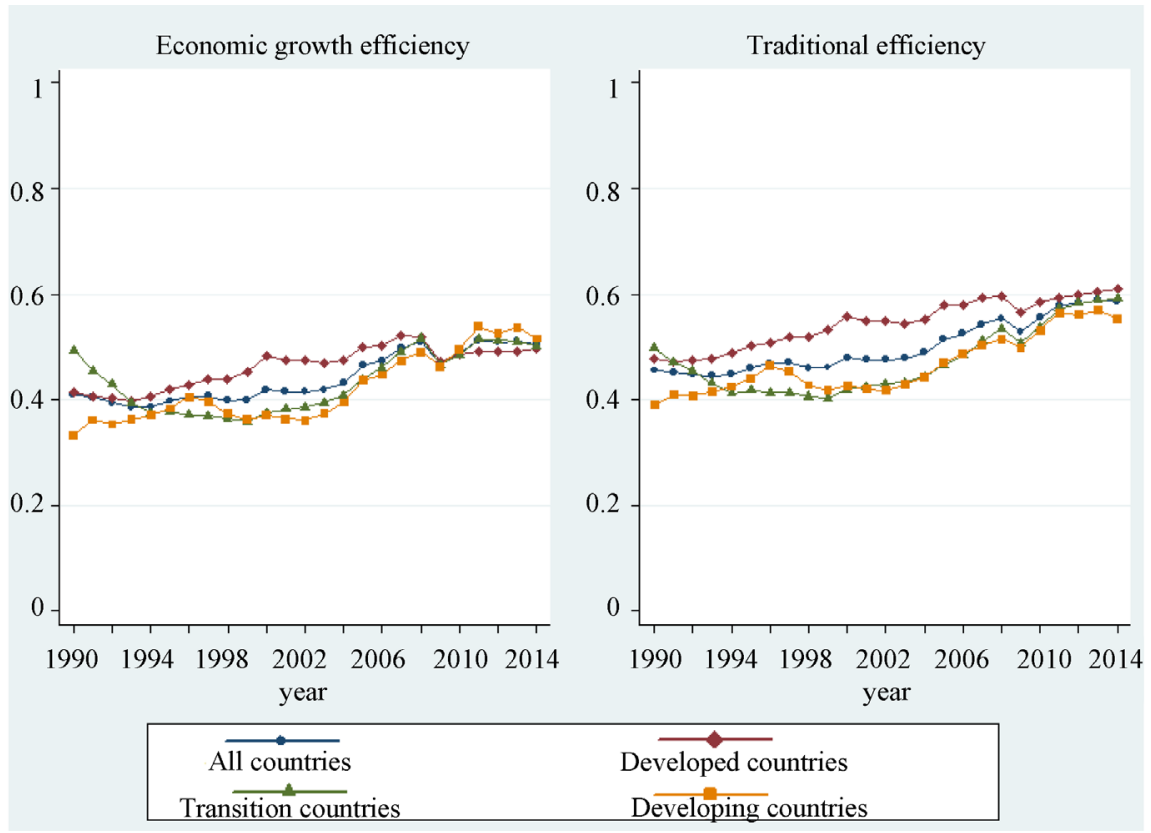

Figure 1. The evolution of economic growth efficiency and traditional efficiency in 60 countries and three major regions (1990-2014).

strong negative impact on the level of production efficiency. Without considering government debt, the average traditional level of efficiency of the developed countries was significantly higher than that of all countries. The traditional level of efficiency of the transition countries and developing countries is the lowest. At the end of 2014, the traditional efficiency of the regional countries showed a divergent state. Interestingly, after incorporating government debt into the production function, developing countries had almost the lowest production efficiency before 2009 and they surpassed the other two major regional countries after that, while the developed countries had the opposite. This showed that the efficiency of production in the developing countries had been greatly improved after the crisis, probably because the financial crisis had a greater negative effect on the other regional countries. Moreover, the economic growth efficiency of countries in various regions in the later period tended to converge. The author concludes that via comparative analysis it is easy to cause deviations if governments judge the economic situation of the country based on traditional efficiency. What's more, adopting the wrong economic policies to improve the economic environment will often fail to achieve ideal results or even worse.

Table 1 specifically reports the average of the economic growth efficiency, traditional efficiency and inefficiency of the 60 countries and three regional countries from 1990 to 2014. The average score of economic growth efficiency of 60 countries is 0.441 , while the traditional efficiency is 0.501 . The decline in production efficiency after considering government debt indicates that over-investment of labor and capital and over-accumulation of debt cause efficiency losses, which applies to other regions. If we ignore the constraints of 
Table 1. Economic growth efficiency, traditional efficiency and decomposition of inefficiency sources in all countries and three regions (1990-2014).

\begin{tabular}{|c|c|c|c|c|c|c|c|}
\hline & & $\begin{array}{c}\text { Efficiency } \\
\text { score }\end{array}$ & $\mathrm{IE}_{\mathrm{L}}$ & $\mathrm{IE}_{\mathrm{K}}$ & $\mathrm{IE}_{\mathrm{Y}}$ & $\mathrm{IE}_{\text {Debt }}$ & $\mathrm{IE}_{\text {Total }}$ \\
\hline \multirow{4}{*}{ 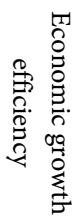 } & All countries & 0.441 & 34.22 & 24.42 & 0.0 & 41.36 & 100 \\
\hline & Developed countries & 0.462 & 35.92 & 24.54 & 0.0 & 39.54 & 100 \\
\hline & Transition countries & 0.433 & 34.08 & 25.21 & 0.0 & 40.71 & 100 \\
\hline & Developing countries & 0.420 & 32.39 & 23.65 & 0.0 & 43.96 & 100 \\
\hline \multirow{4}{*}{ 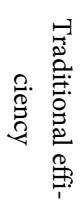 } & All countries & 0.501 & 28.17 & 7.65 & 64.18 & & 100 \\
\hline & Developed countries & 0.545 & 27.16 & 0.40 & 72.44 & & 100 \\
\hline & Transition countries & 0.474 & 32.28 & 7.69 & 60.03 & & 100 \\
\hline & Developing countries & 0.466 & 25.63 & 14.37 & 60.00 & & 100 \\
\hline
\end{tabular}

Note: The data in this table is obtained by calculating the arithmetic mean of the relevant indicators, and each inefficiency value is the share of the total inefficiency value. Source: Author's calculation.

government debt in the process of measuring production efficiency, the efficiency level of the country will be overestimated and thus the economic situation will be misjudged, which explains that economic growth efficiency considering government debt constraints can reflect the real efficiency level. According to the above-mentioned research methods, the economic inefficiency in the production process mainly comes from the inefficiency of inputs and outputs, including labor inefficiency, capital inefficiency, GDP inefficiency and government debt inefficiency. Specifically, considering the debt-constrained production process, the expected output GDP does not appear to be inefficient. The greatest contribution to the inefficiency of economic growth was government debt, which accounted for $41.36 \%$ of the total inefficiency. Second, it was the inefficiency of labor input, accounting for $34.22 \%$. The inefficiency of capital input ranked third, being $24.42 \%$. Regardless of the debts, expected output has the most inefficient value, and the inefficient contributions of labor and capital input are $28.17 \%$ and $7.65 \%$ respectively. This result shows that labor utilization is lower than capital utilization in all countries, indicating that the allocation of labor resources in these countries is not an optimal state. Due to the rapid development of modern science and technology, machinery replaces part of the labor force, which results in an abnormal structure with a low level of labor redundancy and a relatively high level of talent. According to the comparison with traditional efficiency, it is concluded that the most direct and effective way to increase the efficiency of each ineffective decision unit is to enhance the production of expected output GDP. If the amount of redundancy in input and undesired output can be reduced while increasing the expected output, the production efficiency will increase faster.

From the perspective of countries in different regions, the economic growth efficiencies of developed countries, transition countries and developing countries are ranked step by step, with $0.462,0.433$ and 0.420 respectively. To be spe- 
cific, developed countries have the highest efficiency scores, while developing countries have the lowest efficiency scores, which also apply to the situation of traditional efficiency. Debt inefficiency accounts for the largest share of efficiency disaggregation factors among in the region countries, which demonstrates that debt inefficiency has the greatest negative effect on national production efficiency. In addition, government debt has the largest impact on the inefficiency of production in developing countries. This illustrates that developing countries may face the problem of abuse of government debt, the government should pay close attention and take effective measures to implement the assets brought by government debt to the implementation. In terms of other factors, the contribution of labor to the economic production inefficiency exceeds the role of capital, but the relative share varies. The contribution of labor to the inefficient production of developed countries is $35.92 \%$, while the contribution to developing countries is $32.39 \%$, indicating that there is much room for improvement in labor efficiency in developed countries. On the other hand, capital contributes most to the inefficiency of production in transition countries. Therefore, transition countries must pay attention to strengthening the effective use of capital in the production process.

Figure 2 shows the evolutionary trends of the economic growth efficiency and inefficient sources of the 60 countries and region countries during 1990-2014. Although from the point of view of 60 countries or region countries, the trend of traditional efficiency tends to coincide with the efficiency of economic growth, showing a slowly rising trend. This situation presents that the production efficiency of each country during the sample period is in a state of sustained growth.

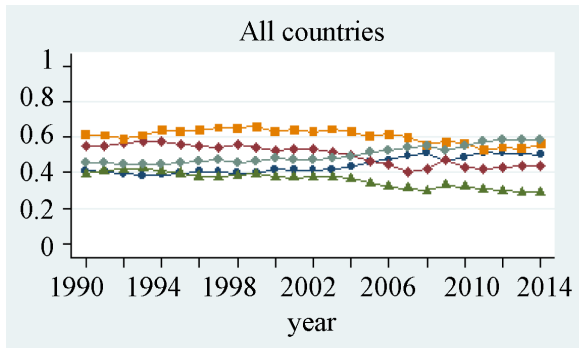

Transition countries
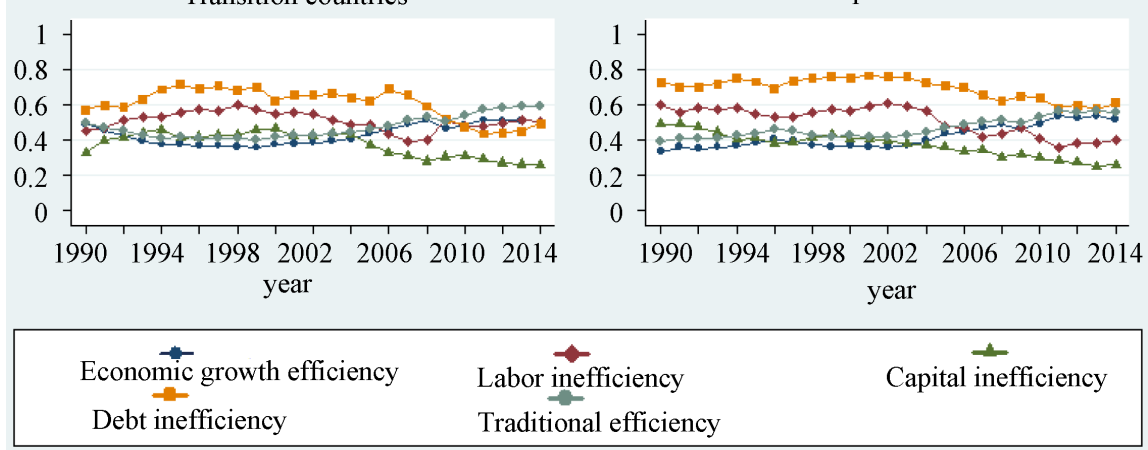

Figure 2. Evolution of average economic growth efficiency and its inefficiency sources in all countries and three major regional countries (1990-2014). 
However, it can still be seen that the traditional efficiency calculated without considering the government debt constraint is indeed higher than the economic growth efficiency, which is consistent with the results of the previous discussion. In terms of the sources of inefficiency, the inefficiency sources of 60 countries are reduced in the order of debt inefficiency, labor inefficiency and capital inefficiency. Debt inefficiency and labor inefficiency both showed an upward trend in the latter period, while capital inefficiency was just the opposite. This shows that debt and labor efficiency are deteriorating, and capital efficiency is improving, which also occurs in developing countries. When the developed countries saw a reversal of the value of debt and labor inefficiency in 1996, the inefficiency of labor and capital showed a downward trend, which meant that the inefficiency of government debt was the main reason to slower economic growth in developed countries. The debt inefficiency of the transition countries in 2006 has dropped significantly. In general, their value is higher than the inefficiency value of labor and capital. At this time, the efficiency of economic growth has risen fastest, indicating that increasing the efficiency of government debt can promote the efficiency of the transition countries. On the whole, debt inefficiencies are more inefficient than labor and capital investment. Debt reduction is the main driving force for promoting production efficiency in all countries and the improvement of labor and capital efficiency has actively promoting effect.

2) Analysis of Total Factor Productivity

Figure 3 depicts the evolution of the average growth rate of economic total factor productivity and traditional total factor productivity over the sample period. From Figure 3(a), we can see that the TFP growth under the constraint of government debt was negative for 60 countries and the three major regional countries during the period of 2008-2009. This was the time period for the largest decline during the inspection period, in line with the economic environment of global crisis. Moreover, it rose rapidly in 2009-2010, which was related to a series of policies that countries used to stimulate economic growth at the time. The growth of developing countries among these countries was the strongest. Although the developing countries were affected by the crisis, the impact was not as good as that of the other two regions and had the highest level of average productivity growth after the crisis, which is consistent with the results of the previous section. At the end of the inspection period, it can be seen that only TFP of the developed countries has achieved positive growth, while the productivity growth rate of 60 countries and other two major regional countries has been negative. There is the problem of deterioration in efficiency or technology regression in transition countries and developing countries. Figure 3(b) shows the trend of the growth of traditional total factor productivity. The time period for peaks and valleys is almost the same as the economical total factor productivity with debt constraints. The difference was that only the productivity growth of developing countries was negative in 2014, indicating that considering the constraints of government debt will reduce the growth of TFP. 


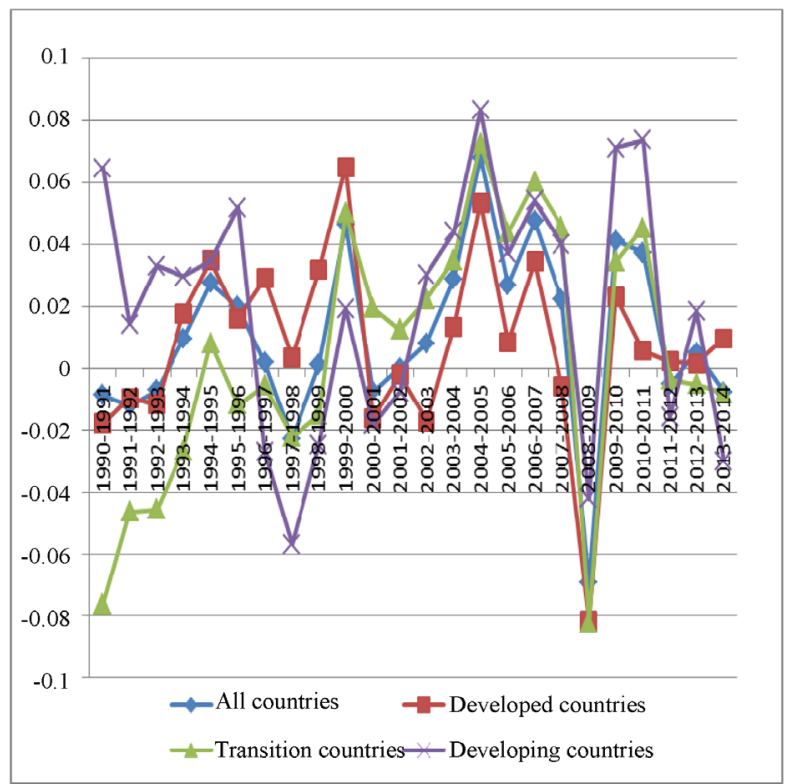

(a)

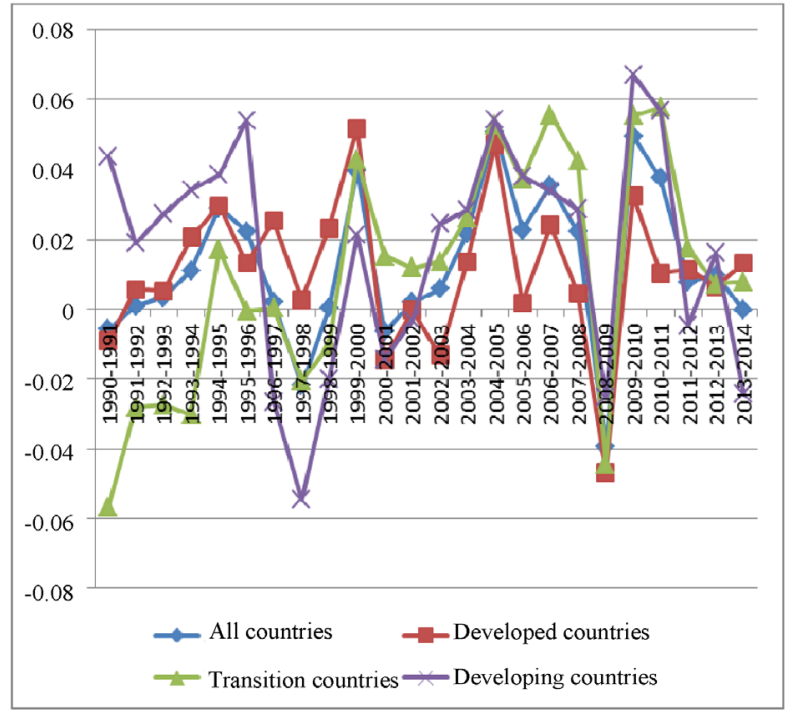

(b)

Figure 3. Evolution of TFP growth rate for all countries and three major regions (1990-2014). (a) Economic TFP growth; (b) Traditional TFP growth.

According to the conventional practice, the TFP is decomposed into efficiency change index and technology change index. By calculating the geometric mean of these indicators, the index values of 60 countries and regional countries can be obtained (see Table 2). From Table 2, it can be seen that the economic TFP and traditional TFP for 60 countries during the inspection period are greater than 1, indicating that the overall productivity is growing. The specific figures are 1.0122 and 1.0101 respectively, and the average growth rate of traditional TFP is $1.22 \%$ while the economical TFP is $1.01 \%$. The growth rate of economic TFP is lower than the traditional TFP. The main difference between these two 
Table 2. Total factor productivity and decomposition of all countries and three regions (1990-2014).

\begin{tabular}{ccccccc}
\hline & \multicolumn{3}{c}{ Without government debts } & \multicolumn{3}{c}{ Considering government debts } \\
\hline & EFCH & TECH & TFPCH & EFCH & TECH & TFPCH \\
\hline All Countries & 1.0046 & 1.0076 & 1.0122 & 1.00212 & 1.0079 & 1.0101 \\
Developed countries & 0.9976 & 1.0129 & 1.0105 & 0.9922 & 1.0154 & 1.0075 \\
Transition countries & 1.0052 & 1.0043 & 1.0095 & 0.9998 & 1.0036 & 1.0034 \\
Developing countries & 1.0133 & 1.0032 & 1.0166 & 1.0174 & 1.0018 & 1.0192 \\
\hline
\end{tabular}

Note: The data in this table is obtained by calculating the geometric mean of the relevant indicators. Source: Author's calculation.

indices is the discrepancy in growth rates between expected and unintended output when the inputs are the same. Specifically, when the growth rate of the expected output is greater than the reduction rate of the unintended output, the traditional TFP will be higher than the economic total factor productivity, which indicates that the GDP growth rate of all countries is greater than the reduction rate of government debt during the sample period. This phenomenon may be attributed to the fact that each country is eagerly pursuing the desired output, that is, the rapid growth of GDP, and neglects the negative impact that the accumulation of debt will have. In addition, both the technology change index and the efficiency change index are also greater than 1, indicating that technological progress and efficiency improvement are the main factors to enhance TFP.

In the three major regional countries, the traditional TFP indexes are all greater than 1 and the productivity growth is ranked in descending order of developing countries, developed countries and transition countries, which are $1.66 \%, 1.05 \%$ and $0.95 \%$ respectively. The main reasons for this phenomenon are the improvement of the average efficiency level in the developing countries and technological progress. The growth rate of developing countries is the largest in the three major regional countries. The efficiency changes and technological progress of the transition countries are also in a state of growth. In addition, the average efficiency of the developed countries is degeneration while the technological progress is far higher than that of the transition countries, which shows that technological progress has a greater effect on the growth of TFP. The economy TFP is the same as that of the traditional TFP. The difference is that the efficiency changes in the transition countries happen to retrogress, and are the same as those in the developed countries. Another unusual phenomenon is that the growth rate of traditional TFP in both developed and transition countries is higher than that of economic TFP. However, the growth rate of traditional TFP is $1.66 \%$ for developing countries, which is lower than the growth rate of economy TFP about $1.92 \%$. This shows that the decrease in government debt is greater than GDP growth, probably because this stage is on the left of the inverted U-shape of government debt and economic growth. At this time, reducing the scale of government debt will restrain economic growth. 


\section{Analysis of Affecting Factors on Economic Growth Efficiency and Productivity}

In order to further study the factors affecting the efficiency of economic growth and productivity under the government debt constraint, this paper selects indicators such as industrial structure, investment rate, opening degree, human capital, and financial development as explanatory variables by learning from the literature of the predecessors. The variables are described as follows: 1) Industrial Structure (IS): The industrial structure of each country reflects development focus and the level of development about this country, which closely related to the economy of a country. It is usually expressed as the proportion of industrial added value to GDP. The data comes from the WDI database. 2) Investment rate (INV): It is measured by the proportion of total investment in GDP, and the data comes from the PWT 9.0 database. 3) Degree of openness to the outside world (OP): the data is represented by the ratio of a country's imports and exports to its GDP and is able to be required from the WDI database. Since the deepening of the degree of opening to the outside world among countries has brought a qualitative leap to the economies of various countries, the impact of opening to the outside world on economic growth is self-evident. 4) Human capital (HC): $\mathrm{Hu}$ man capital is different from material capital and is an effective measure of human production knowledge, health quality and skills. Its contribution to economic growth is much greater than that of physical capital. This data is based on the average number of years of schooling and the probability of returning to school and is derived from the PWT 9.0 database. 5) Financial Development (FD): The financial development indicators in this paper are the combined indicators measured in terms of the depth, availability and efficiency of financial institutions and financial markets. The data comes from the IMF's IFS (International Financial Statistics).

The paper regards the economic growth efficiency, labor efficiency, capital efficiency and debt efficiency as dependent variables to facilitate the analysis, and the range of values of these variables is between 0 and 1, which belongs to truncated data. If ordinary least squares estimation is employed to carry out regression analysis for this model, the results obtained are biased and inconsistent. Therefore, this paper applies the tobit model to solve this problem. To be further, the Hausman test on the regression model of TFP under the government debt constraint has a very significant result, so a fixed-effect regression model is adopted. The dependent variables of models (1)-(5) are economic growth efficiency, labor efficiency, capital efficiency, debt efficiency and TFP on government debt constraints (Table 3).

The industrial structure is significantly positive for labor efficiency, capital efficiency and debt efficiency at the level of $1 \%$, indicating that the greater the proportion of industrial added value in GDP, the more effective the reduction in labor, capital and debt redundancy. Thus this condition will enhance the efficiency of economic growth. On the one hand, industrial development will 
Table 3. Regression model.

\begin{tabular}{|c|c|c|c|c|c|}
\hline Dependent variables & model (1) & model (2) & model (3) & model (4) & model (5) \\
\hline Independent variables & score & el & ek & edebt & $\mathrm{tfp}$ \\
\hline \multirow[t]{2}{*}{ model IS } & $0.3968^{* * *}$ & $0.4152^{\star * *}$ & $0.4627^{* * *}$ & $0.4242^{\star * *}$ & $0.3310^{* * *}$ \\
\hline & -0.0507 & -0.0772 & -0.0802 & -0.0844 & -0.0627 \\
\hline \multirow[t]{2}{*}{ INV } & $-0.5037^{\star * *}$ & $-0.6936^{* * *}$ & $-0.5427^{\star * *}$ & -0.0721 & -0.0253 \\
\hline & -0.0559 & -0.0852 & -0.0889 & -0.0931 & -0.0452 \\
\hline \multirow[t]{2}{*}{ OP } & $0.0421^{\star * *}$ & $0.0780^{\star * *}$ & $0.0323^{\star * *}$ & -0.0104 & $0.0334^{\star * *}$ \\
\hline & -0.0058 & -0.0089 & -0.0092 & -0.0097 & -0.0114 \\
\hline \multirow[t]{2}{*}{$\mathrm{HC}$} & $0.0831^{\star \star *}$ & $0.0706^{\star * *}$ & $0.1227^{\star \star \star}$ & $0.0746^{* * *}$ & -0.002 \\
\hline & -0.0075 & -0.0115 & -0.0119 & -0.0125 & -0.0173 \\
\hline \multirow[t]{2}{*}{ FD } & $0.1149^{* * *}$ & $0.1150^{* * *}$ & $0.0964^{* * *}$ & $0.2138^{\star * *}$ & $0.0786^{* * *}$ \\
\hline & -0.022 & -0.0335 & -0.0347 & -0.0366 & -0.0285 \\
\hline \multirow[t]{2}{*}{ Constant } & $0.1168^{\star * *}$ & $0.2171^{\star * *}$ & $0.2239^{* * *}$ & -0.0222 & $0.8553^{* * *}$ \\
\hline & -0.0236 & -0.0358 & -0.0371 & -0.0392 & -0.046 \\
\hline \multirow[t]{2}{*}{ sigma Constant } & $0.1324^{* * *}$ & $0.2011^{\star * *}$ & $0.2067^{* * *}$ & $0.2205^{\star * *}$ & \\
\hline & -0.0024 & -0.0038 & -0.0042 & -0.004 & \\
\hline Observations & 1500 & 1500 & 1500 & 1500 & 1440 \\
\hline
\end{tabular}

Note: "*” indicates $p<0.1$, “**” indicates $p<0.05$, “***” indicates $p<0.01$.

increase employment demand in the market, the introduction of machinery and equipment and talents and greatly the utilization efficiency of labor and capital factors. On the other hand, the improvement of industrial level can indirectly decrease the amount of government's borrowing to achieve the purpose of promoting economic growth. Similarly, the industrial structure also has a positive role in promoting TFP under government debt constraints and this can be explained from the perspective of technological progress. The development of industry must be accompanied by the rapid development of mechanization and technology. As the above analysis, technological progress is a major factor on the improvement of TFP.

The coefficient of investment on labor and capital production efficiency is negative and significant, and there is no significant effect on debt efficiency. Reducing the amount of labor, capital and debt redundancies is an effective way to increase the efficiency of economic growth. The paper finds that the investment rate has an effect on the economic growth efficiency through labor and capital input factors and the effect is negative. Research shows that there is a reasonable investment rate that makes the economic growth steadily. Logically speaking, high investment rates should represent high economic growth efficiency, but Consumption levels have plummeted due to investment mistakes and high investment rates, which will lead to opposite results. For example, more labor-intensive production techniques should be used for labor-intensive coun- 
tries. If more investment is made into capital elements due to the unreasonable allocation of investment, there will be insufficient labor input and excessive capital investment. In addition, the balance between investment and consumption is also a point that cannot be ignored in promoting economic growth. The investment rate has no significant effect on TFP under government debt constraints, which is related to the phenomenon that most countries invest less in high-tech research and development.

Like the investment rate, the degree of opening to the outside world also affects the economic growth efficiency by influencing the input of labor and capital. It is only because the degree of opening to the outside world has a significant role in promoting economic growth efficiency. The increase in the degree of openness to the outside world means that labor and capital can flow among all countries, allowing countries to better allocate resources and achieving a reasonable division of labor and efficient accumulation of capital. As a result, it is helpful to increase labor and capital production efficiency. Not only that, as countries continue to deepen their openness to the outside world, they are conducive to expanding domestic demand, attracting foreign investment, learning advanced foreign technology and management experience and enhancing technological absorptive capacity. The technology spillover effect will increase the human capital stock of professionals and promote the technological progress of all countries. Therefore, the deepening of the degree of opening to the outside world will bring about a positive effect on TFP under government debt constraints.

There is a significant positive correlation between human capital and labor, capital, and debt efficiency. According to the coefficient of related variables, we can see that human capital exerts the greatest effect on capital production efficiency, which is in line with forecast that human capital contributes to promoting economic growth efficiency. Human capital as the source of technological progress should have promoted the growth of TFP in terms of endogenous growth theory. However, this paper finds that human capital has no significant effect on TFP under debt constraints. The study of Vandenbussche et al. [21] found that the part of human capital with higher education has a significant role in promoting TFP, while primary education is not significant. That is to say, this phenomenon may be took place because the rate of average years of schooling and back-to-school education is not high enough for all countries during the study period.

The performance of financial development is reflected in the two-way development of financial institutions and financial markets and the continuous deepening of financial structure plays a crucial role in promoting economic growth. Among the factors of financial development, the role of financial development on labor, capital and debt efficiency is also significantly positive, which is conducive to improving the efficiency of economic growth. Gu Yongkun and Liu Yongtian [22] pointed out that financial development plays a central role on the 
process of resource allocation and has a diversion effect on factors of production, making resources flow to sectors with higher marginal productivity. Therefore, financial development can strengthen production efficiency of labor and capital investment in the production process. Moreover, financial development is helpful to the rational use of funds, decreasing the rate of non-performing loans and boosting the efficiency of the use of government debt. The relationship between financial development and TFP under debt-constrained is significantly positive at the $1 \%$ level. The regions with higher financial development efficiency are conducive to triggering technological spillover benefits, attracting foreign investment into the development of other countries, and thus promoting the increase of productivity in each country.

\section{Conclusions and Suggestions}

The paper adopts the SBM method and the GML productivity index to measure the economic growth efficiency and inefficient source, total factor productivity and its decomposition about 60 countries under government debt constraints during 1990-2014. Moreover, the author compares them with traditional efficiency and productivity and explores the economic growth efficiency and productivity factors under debt constraints. The results of this paper are as follows.

Firstly, 2009 is an important turning point for traditional efficiency and economic growth efficiency. Compared with developed countries and transition countries, the economic growth efficiency of developing countries has the fastest growth speed and is inconsistent with the results of traditional efficiency. In addition, it has been found that the average efficiency of economic growth considering the government debt constraint is less than the traditional efficiency and the economic growth efficiency is more in line with the actual value. The economic growth efficiency and traditional efficiency of the three major regional countries are decreasing in the order of developed countries, transition countries and developing countries. In terms of inefficient sources, the inefficiency of government debt has the largest share in 60 countries, accounting for $41.36 \%$. Labor inefficiency and capital inefficiency rank second and third respectively, at $34.22 \%$ and $24.42 \%$. The contribution of debt inefficiency, labor inefficiency and capital inefficiency in the three major regional countries is also reduced in turn, but there are differences in relative shares. In 2014, capital inefficiency gradually declined, and debt inefficiency and labor inefficiency were the opposite. At the same time, economic growth efficiency was slowly rising. The analysis shows that reducing the inefficiency of labor, capital and government debt is an effective way to elevate the efficiency of economic growth.

Secondly, the paper found that, the TFP of 60 countries and in the three major regional countries after considering debt constraints experienced negative growth during 2008-2009, and then rose rapidly in 2009-2010. This indicated that after the crisis the countries adopted policies to stimulate economic growth which have achieved great results. Like efficiency, TFP measured without considering government debt constraints will be overestimated, giving residents and 
governments an illusion of high productivity, which is detrimental for policy makers to make accurate judgments. A comparative analysis of traditional TFP and economic TFP shows that although this two TFP for 60 countries and in the three regional countries has achieved positive growth, there are differences in relative growth. According to the decomposition of the GML index, efficiency changes and technological progress are the main driving forces for the growth of TFP. There is a problem of deterioration in efficiency in developed countries and transition countries, but the level of technological progress is higher than that of developing countries. This shows that developed countries and transition countries more focused on scientific and technological research and development than developing countries, and they have strong economic strength, advantages of excellent talent pool and advanced technology and equipment.

This article also analyzes the affecting factors of the economic growth efficiency and productivity under the constraints of government debt, and finds that the industrial structures, openness to the outside world, human capital and financial development have a significant positive impact on the economic growth efficiency, while the effect of investment rate on economic growth efficiency is negative. Labor efficiency, capital efficiency and debt efficiency are the three major ways of influencing economic growth efficiency. In addition, the fixed effect model shows that the industrial structure, degree of opening to the outside world and financial development have a significant positive correlation with the economy TFP, and investment rate and human capital have no significant effect on productivity.

The results of this paper have important policy implications. The government must take into account the constraints of government debt when formulating economic policies, because neglecting the constraints of government debt will overestimate the efficiency and productivity of economic growth. Enhancing the debt efficiency is the most important way to increase the efficiency of economic growth. Therefore, governments should strengthen the rational use of government debt. At the same time, adopting effective measures to increase the allocation efficiency of labor and capital will further promote the increase of efficiency level. Developed countries and transition countries should focus on improving efficiency. Technological progress is the main driving force for countries to achieve economical total factor productivity growth. In order for countries to achieve rapid growth in economic growth efficiency and productivity, they should pay attention to the problems caused by government debt in the production process and make full use of the role of macroeconomic regulation. Then they can take appropriate measures based on the above analysis of the affecting factors of economic growth efficiency and productivity, improving the economy by quality and quantity.

\section{Conflicts of Interest}

The authors declare no conflicts of interest regarding the publication of this paper. 


\section{References}

[1] Reinhart, C.M. and Rogoff, K.S. (2011) From Financial Crash to Debt Crisis. American Economic Review, 101, 1676-1706. https://doi.org/10.1257/aer.101.5.1676

[2] Reinhart, C.M. and Rogoff, K.S. (2010) Growth in a Time of Debt. American Economic Review, 100, 573-578. https://doi.org/10.1257/aer.100.2.573

[3] Cecchetti, S.G., Mohanty, M.S. and Zampolli, F. (2011) The Real Effects of Debt. Social Science Electronic Publishing, 68, 145-196.

[4] Minea, A. and Parent, A. (2012) Is High Public Debt Always Harmful to Economic Growth? Reinhart and Rogoff and Some Complex Nonlinearities. Working Papers 201218, CERDI.

[5] Checherita-Westphal, C. and Rother, P. (2012) The Impact of High Government Debt on Economic Growth and Its Channels: An Empirical Investigation for the Euro area. European Economic Review, 56, 1392-1405. https://doi.org/10.1016/j.euroecorev.2012.06.007

[6] Pescatori, A., Sandri, D. and Simon, J. (2014) Debt and Growth: Is There a Magic Threshold? International Monetary Fund, IMF Working Paper No. 14/34.

[7] Salotti, S. and Trecroci, C. (2016) The Impact of Government Debt, Expenditure and Taxes on Aggregate Investment and Productivity Growth. Economica, 83, 356-384. https://doi.org/10.1111/ecca.12175

[8] Swamy, V. (2015) Government Debt and Economic Growth-Decomposing the Cause and Effect Relationship.

[9] Calderón, C. and Fuentes, J.R. (2013) Government Debt \& Economic Growth. Inter-American Development Bank, Washington DC.

[10] Afonso, A. and Jalles, J.T. (2013) Growth and Productivity: The Role of Government Debt. International Review of Economics \& Finance, 25, 384-407. https://doi.org/10.1016/j.iref.2012.07.004

[11] Liu, J.L. (2013) Research on the Rational Scale of Government Debt Based on Economic Growth Perspective: Evidence from OECD. Economic Issues, 12, 25-30.

[12] Liu, H.Z., Yang, G.Y. and Yin, L. (2014) Government Debt, Economic Growth and Nonlinear Effects. Statistical Research, 4, 29-38.

[13] Cheng, Y.D. and Gong, L.T. (2014) The Impact of Government Debt on Economic Growth and Its Channels. Journal of Quantitative \& Technical Economic Research, 31, 22-37.

[14] Cheng, Y.D. and Gong, L.T. (2015) The Economic Growth Effect and Influencing Channel of Foreign Debt-Comparison of Developed Countries and Developing Countries. Journal of Quantitative \& Technical Economics Research, 32, 108-123.

[15] Tone, K. (2001) A Slacks-Based Measure of Efficiency in Data Envelopment Analysis. European Journal of Operational Research, 130, 498-509. https://doi.org/10.1016/S0377-2217(99)00407-5

[16] Li, J. (2013) China's Economic Growth Efficiency under the Dual Constraints of Energy and Environment-Analysis Based on Unexpected Output Model. Science and Technology Management Research, 33, 209-214.

[17] Zhang, W., Zhao, S., Long, H., et al. (2015) Economic Growth Efficiency Based on SBM Method and Decomposition of Total Factor Productivity: Taking Sichuan Province as an Example. Finance and Economics, No. 8, 100-111.

[18] Wang, Z. and Feng, C. (2015) Sources of Production Inefficiency and Productivity 
Growth in China: A Global Data Envelopment Analysis. Energy Economics, 49, 380-389. https://doi.org/10.1016/j.eneco.2015.03.009

[19] Chung, Y.H., Färe, R. and Grosskopf, S. (1997) Productivity and Undesirable Outputs: A Directional Distance Function Approach. Journal of Environmental Management, 51, 229-240. https://doi.org/10.1006/jema.1997.0146

[20] Oh, D. (2010) A Global Malmquist-Luenberger Productivity Index. Journal of Productivity Analysis, 34, 183-197. https://doi.org/10.1007/s11123-010-0178-y

[21] Vandenbussche, J., Aghion, P. and Meghir, C. (2006) Growth, Distance to Frontier and Composition of Human Capital. Journal of Economic Growth, 11, 97-127. https://doi.org/10.1007/s10887-006-9002-y

[22] Gu, Y. and Liu, Y. (2017) Financial Development and Industrial Structure Adjustment-Based on the Analysis Perspective of Production Factor Distribution. Journal of Finance, No. 2, 98-109. 